\title{
Study on reasons of dropout of immunization in children in selected slum area of Dhaka city, Bangladesh
}

\author{
Latifur Rahman ${ }^{1}$, Haridas Biswas ${ }^{2}$, Tofazzel Hossain ${ }^{3}$, Abdul Mazid Khan ${ }^{4}$, Ishaq Ali Khan ${ }^{5}$
}

\begin{abstract}
${ }^{1}$ Associate Professor and Head, Department of Community Medicine; ${ }^{2}$ Associate Professor \& Head, Department of Forensic Medicine; ${ }^{3}$ Associate Professor, Department of Pharmacology; ${ }^{5}$ Assistant Professor, Department of Cardiology, Diabetic Association Medical College, Faridpur. ${ }^{4}$ Lecturer, Department of Community Medicine, Faridpur Medical College, Faridpur, Bangladesh.
\end{abstract}

\begin{abstract}
The Expanded Programme on Immunization is one of the most cost-effective, powerful and safe public health interventions. This cross-sectional study carried out at a selected slum in Dhaka city, Bangladesh to examine the reasons of dropout of immunization in children. Mothers having children 11-23 months with history of EPI dropout were included in the study. A total of 128 mothers were interviewed. Out of 128 respondents $32.8 \%$ were in the age of 26 $-30 \mathrm{yrs} ; 96.9 \%$ were married, $65.7 \%$ were housewife, $62.5 \%$ had $4-6$ members in the family, $50.78 \%$ had primary education \& rest $10.15 \%$ had secondary level education. Approximately $53.1 \%$ of the husbands of the respondents were day laborers, and $57.8 \%$ of the family had a monthly income in range of Tk. 2001-3000. Out of 128 dropout children, $31.2 \%$ were in the age group 11-13 moths and 28.2\% were in the age group 20 months and above. During the interview, respondents were able to show the EPI Card of their children. The main reasons for dropping out were a lack of awareness to complete the vaccination schedule $(25 \%)$, and illness of child $(21.9 \%)$. The other reasons were fear of reaction $(9.4 \%)$ and business of the mother $(9.4 \%)$. There is a need to intensify efforts to increase access for immunization, strengthen surveillance and promote health education to reduce the drop-outs in slum areas.
\end{abstract}

Keywords: EPI, Vaccination, Dropout, Slum areas, Dhaka.

\section{Introduction}

The Expanded Programme on Immunization (EPI) is one of the most cost-effective, powerful and safe public health interventions and is considered to be one of the main programs for achieving Millennium Development Goal 4 (MDG 4). ${ }^{1,2}$ Vaccines continue to have a tremendous impact on public health, saving millions of lives each year. In Bangladesh, EPI was launched on $7^{\text {th }}$ April 1979 to reduce the mortality, morbidity and disability of children. ${ }^{3}$ The diseases which are preventable by immunization usually strike the children early during infancy or the preschool period. In Bangladesh, infant and under five mortality rates were 49 and 52 per 1,000 live births respectively in 2009 which was still very high. ${ }^{4}$ Though national EPI coverage is good in Bangladesh, EPI coverage in the slum areas is reported to be low. ${ }^{5}$ It was reported that the awareness of EPI, knowledge of vaccines, and acceptance of complete doses of vaccines are higher among the middle class and lower middle class compared to slum dwellers. $^{6}$ Acceptance of complete doses of vaccines is highest among the middle class (75\%), intermediate among the lower middle class (60\%), and lowest among slum dwellers $(48 \%){ }^{6}$

In Dhaka city, an estimated 3.4 million people live in some 5000 slums. ${ }^{7}$ Slum living has important social and health consequences. The majority of the slum dwellers migrated to Dhaka for economic reasons, and had

\section{Practice Points}

- EPI is one of the most cost-effective, powerful and safe public health interventions

- Lack of awareness among mothers as the most important cause for dropouts in vaccination programs in slum areas.

- Dropout rate is greater among younger children and family size had no relationship with the reasons of dropout.

- Age, occupation, and the socioeconomic condition of mothers were identified as the contributory factors for higher dropout rate.

- There is a need to intensify efforts to increase access for immunization, strengthen surveillance and promote health education to reduce the drop-outs in slum areas.

unacceptable levels of malnutrition, hygiene and health, deprivation of essential services and high infant and maternal mortality. To make a uniform progress in the health service, effective measures in EPI can save the slum children and this would be helpful to achieve the target of MGD. The aim of this study was to examine the reasons of dropout of immunization in children in slum areas of Dhaka city, Bangladesh.

Correspondence: Dr. Latifur Rahman' Associate Professor \& Head, Dept. of Community Medicine, Diabetic Association Medical College, Faridpur. E-mail: latifur50@yahoo.com.

South East Asia Journal of Public Health 2012;2(1):64-67. (C) 2012 Rahman et al., publisher and licensee Public Health Foundation Bangladesh. This is an Open Access article which permits unrestricted non-commercial use, provided the original work is properly cited. 


\section{Materials and methods}

A cross-sectional study was conducted among 128 respondents of two slums, Godaraghat and Vasantek slums, of Dhaka city, Bangladesh. Mothers with children of 11-23 months of age with a history of EPI dropouts were included in the study. The study was done from 1st July to 30th September, 2008. Data was collected through a pre-tested structured questionnaire and through face to face interviews by the researcher himself.

\section{Results}

The detailed socio-demographic status of the respondents is show in Table 1. Out of 128 respondents $32.8 \%$ were in the age of $26-30 \mathrm{yrs} ; 96.9 \%$ were married, $65.7 \%$ were housewife, $62.5 \%$ had $4-6$ members in the family, and $50.78 \%$ had primary level education. The mean age of the respondents was 27.5 with SD 6.3 and the average family size was 4.7 .

Table 1: Socio-demographic status of the respondents

\begin{tabular}{|c|c|}
\hline Variables & Frequency (\%) \\
\hline \multicolumn{2}{|l|}{ Age } \\
\hline $16-20 \mathrm{yrs}$ & $20(15.6 \%)$ \\
\hline $21-25$ yrs & $28(21.9 \%)$ \\
\hline $26-30$ yrs & $42(32.8 \%)$ \\
\hline $31-35$ yrs & $24(18.7 \%)$ \\
\hline $36-40$ yrs & $10(7.9 \%)$ \\
\hline $41+\mathrm{yrs}$ & $4(3.1 \%)$ \\
\hline \multicolumn{2}{|l|}{ Occupation } \\
\hline Housewife & $84(65.7 \%)$ \\
\hline Maid servant & $24(18.8 \%)$ \\
\hline Business & $10(7.8 \%)$ \\
\hline \multicolumn{2}{|c|}{ Educational Status } \\
\hline Illiterate & $50(39.06 \%)$ \\
\hline Primary & $65(50.78 \%)$ \\
\hline Secondary & $13(10.15 \%)$ \\
\hline \multicolumn{2}{|l|}{ Family size } \\
\hline$<4$ & $36(28.1 \%)$ \\
\hline $4-6$ & $80(62.5 \%)$ \\
\hline $7+$ & $12(9.4 \%)$ \\
\hline \multicolumn{2}{|c|}{ No of children in the family } \\
\hline 1-2 children & $68(53.1 \%)$ \\
\hline 3-4 children & $50(39.1 \%)$ \\
\hline 5-6 children & $6(4.7 \%)$ \\
\hline $7+$ children & $4(3.1 \%)$ \\
\hline \multicolumn{2}{|c|}{ Husband's occupation } \\
\hline Day labor & $68(53.1 \%)$ \\
\hline Business & $40(31.3 \%)$ \\
\hline Service & $16(12.5 \%)$ \\
\hline Others & $4(3.1 \%)$ \\
\hline \multicolumn{2}{|c|}{$\begin{array}{l}\text { Monthly income of family } \\
\text { (Taka) }\end{array}$} \\
\hline $500-1000$ & $2(1.6 \%)$ \\
\hline $1001-2000$ & $18(14.0 \%)$ \\
\hline $2001-3000$ & $74(57.8 \%)$ \\
\hline $3001+$ & $34(26.6 \%)$ \\
\hline
\end{tabular}

Approximately $53.1 \%$ of the husbands of the respondents were day laborers, and $57.8 \%$ of the family had a monthly income in range Tk. 2001-3000.

Table 2 shows the age distribution of dropout children; out of 128 children $31.2 \%$ were in the age group 11-13 moths and $28.2 \%$ were in the age group 20 months and above. During the interview, respondents were able to show the EPI Card of their children.

Table 2: Age distribution of dropout children

\begin{tabular}{|l|c|}
\hline \multicolumn{1}{|c|}{ Age of children } & Frequency (\%) \\
\hline $11-13$ month & $40(31.2)$ \\
\hline $14-16$ month & $24(18.8 \%)$ \\
\hline $17-19$ month & $28(21.8 \%)$ \\
\hline $20+$ month & $36(28.2 \%)$ \\
\hline
\end{tabular}

Table 3 shows that the major causes for dropout which include lack of awareness of need for further immunization $(25 \%)$ and illness of child (21.9\%). Age, occupation, and socioeconomic condition of mothers are contributory factors of dropout of EPI vaccination. There is an association between the above factors and dropout of EPI vaccination, which is statically significant $(\mathrm{P}<0.05)$.

Table 3: Stated reasons of dropout of EPI vaccination (children 11-23 month)

\begin{tabular}{|l|c|}
\hline \multicolumn{1}{|c|}{ Reasons of dropout } & Frequency (\%) \\
\hline $\begin{array}{l}\text { Unaware of need for further } \\
\text { immunization }\end{array}$ & $32(25 \%)$ \\
\hline Fear of side reaction & $12(9.4 \% 0$ \\
\hline $\begin{array}{l}\text { Wrong ideas about contra indica- } \\
\text { tion }\end{array}$ & $8(6.3 \%)$ \\
\hline $\begin{array}{l}\text { Place/time of immunization un- } \\
\text { known }\end{array}$ & $8(6.3 \%)$ \\
\hline Illness of child & $282(1.9 \%)$ \\
\hline Mother too busy & $12(9.4 \%)$ \\
\hline Time inconvenient & $10(7.8 \%)$ \\
\hline Place of immunization to far & $6(4.6 \%)$ \\
\hline $\begin{array}{l}\text { Family problem including illness } \\
\text { of mother }\end{array}$ & $4(3.1 \%)$ \\
\hline Long waiting time & $4(3.1 \%)$ \\
\hline Others & $4(3.1 \%)$ \\
\hline
\end{tabular}

\section{Discussion}

The aim of this study was to determine the reasons of dropout of EPI vaccination of children. In this study, a quarter of the children were dropped out due to the lack of awareness of importance of further immunization among mothers and more than one-fifth of the children were not taken to the immunization center by mothers due to the illness of their children. These findings were supported by the findings of the other studies conducted in urban areas of Bangladesh. ${ }^{5,6,8,9}$ Studies conducted in the Dhaka district (urban and rural) highlighted that the major reason for incomplete vaccination was lack of knowledge regarding subsequent doses (46\%); the number of responses were much higher than the present 
study. ${ }^{10}$ Another study examined that child immunization coverage in rural hard-to-reach haor areas of Bangladesh and identified the following reasons for low complete immunization coverage: irregular/cancelled EPI sessions, fear of side effects, mothers' poor knowledge about benefits of complete vaccination, lack of mothers' knowledge about EPI sessions, geographical barriers etc. ${ }^{11}$

From this study it is evident that the mean age of the respondents was 27.5 years which is similar ( 25 years) to the study conducted by Khan et al. ${ }^{6}$ The study also demonstrated that maximum dropout occurred among the middle aged group of mothers (26-30 years). This is also similar to the study by Khan et al., ${ }^{6}$ where researches showed that young mothers $<25$ years are more likely to complete vaccination than older mothers. However, the study by Tariqul Islam et al. ${ }^{12}$ showed that dropout cases were more numerous among younger mothers (22.5-26.5 years). This variation may be due to a natural variability or due to differences in sample size and sampling area.

With regard to the occupation of the respondents, $65.7 \%$ were housewives and most of the respondents' husbands $(53.1 \%)$ were day laborers. The study also disclosed that $39.06 \%$ of the respondents were illiterate and approximately half of the mothers had primary level education. This low education level of parents certainly had an impact on the rate of EPI vaccination dropouts ${ }^{6}$ and, probably, this low literacy rate created a lack of awareness among mothers in regards to the uptake of vaccination.

In this study, the average family size was 4.7 and approximately one third of the families had 4-6 members. However, family size had no relationship with the reasons of dropout. The average number of children was 2.7 , and $53.1 \%$ of the families had $1-2$ children while $39.1 \%$ had 3-4 children. The study conducted by Tariqul Islam et al. ${ }^{12}$ showed similar findings: $57 \%$ of the respondents had 1-2 children and 40\% had 3-4 children.

We found that the majority of the children who dropped out $(31.2 \%)$ were in the 11-23 months age group which indicates that the dropout rate is greater among younger children. In the previous studies, ${ }^{6,12}$ the age distribution of children who dropped out were not mentioned.

The prevalence of vaccine-preventable diseases is more common in urban slums due to high density of population and poor hygienic conditions. One-quarter of the population of the Dhaka City Corporation lives in slum households. ${ }^{13}$ In Bangladesh, although $75 \%$ of children aged 12-23 months are fully immunized, ${ }^{5}$ the coverage in urban slums remains low as evident from this study and other previous studies. According to EPI Survey Coverage Report 2011, the proportion of fullyimmunized children in the Dhaka City Corporation was $68.4 \%$, whereas the coverage in slums was $59.5 \% .{ }^{14}$ Specific programs targeted to slum areas could improve the quality of life of the urban poor, decrease the vaccination dropout, and increase the immunization coverage. ${ }^{15,16}$

\section{Conclusion}

This study has highlighted lack of awareness among mothers as the most important cause for dropouts in vaccination programs in slum areas. Age, occupation, and the socioeconomic condition of mothers were identified as the contributory factors for higher dropout rates. Effective intervention is needed to improve full immunization coverage in slum areas by strengthening the EPI programs and mobilizing the community, modifying the EPI session schedule, opening additional and more convenient outreach sites, community involvement, and improved training for healthcare providers.

\section{References}

1. Bloom DE. The value of vaccination. Adv Exp Med Biol 2011;697:1-8.

2. WHO. Scaling up the Expanded Programme on Immunization to meet global and regional targets. Technical Paper no. EM/RC58/4. Cairo: World Health organization, Regional Office for the Eastern Mediterranean, 2011.

3. WHO. The Expanded Programme on Immunization in South East Asia. SEARO Reginal Health Papers NO. 12.

4. Majumder MAA. World Health Statistics 2011: How does Bangladesh compare with other SouthEast Asian countries? South East Asia J Public Health 2011;1:4-8.

5. Uddin MJ, Larson CP, Oliveras E, Khan AI, Quaiyum MA, Saha NC. Child immunization coverage in urban slums of Bangladesh: impact of an intervention package. Health Policy Plan 2010;25:5060.

6. Khan, M, Rahman S, Chowdhury JH, Kamal GM. Assessment of EPI communication interventions in urban areas: final report. Dhaka: Associates for Community and Population Research, 1990.

7. Center for Urban Studies, National Institute of Population, research and Training (NIPORT) and Measure Evaluation. Slums of Urban Bangladesh: Mapping and Census 2005. Dhaka: Centre for Urban Studies, 2006.

8. Laston SL, Baqui AH, Paljor N, Silimperi DR. Immunization beliefs and coverage in Dhaka urban slums. Urban FP/MCH Working paper No. 5, ICDDR,B; 1993.

9. Atkinson SJ, Cheyne J. Immunization in urban areas: issues and strategies. Bull World Health Org 1994;72:183-94.

10. Khan MN, Rahman ML, Awal Miah A, Islam MS, Musa SA, Tofail F. Vaccination coverage survey in Dhaka District. Bangladesh Med Res Counc Bull 2005;31:46-53.

11. Uddin MJ, Larson CP, Oliveras E, Khan AI, Quaiyum MA, Saha NC. Child immunization coverage in rural hard-to-reach haor areas of Bangladesh: possible alternate strategies. Asia Pacific J Pub Health 2009:21: 8-18.

12. Tariqul Islam et al, KAP study of the rural people towards immunization, June 1985, NIPSOM, Mohakhali, Dhaka. 
13. Perry H, Nurani S, Quaiyum A, Jinnah S. Barriers to Immunization among women and children living in slums of Zone 3 of Dhaka city, Bangladesh. ICDDR,B Working Paper no. 166. Dhaka: ICDDR,B: Centre for Health and Population Research., 2007.

14. Directorate General of Health Services (DGHS). EPI coverage evaluation survey. Dhaka: Expanded Programme on Immunization, Ministry of Health and Family Welfare, Government of Bangladesh, 2011.
15. Chandra R, Srivastava VK, Nirupam S. Impact of Urban Basic Services on immunization coverage in a slum area of northern India. Asia Pac J Public Health 1992-1993;6:153-5.

16. Rahman M, Islam MA, Mahalanabis D. Mothers' knowledge about vaccine preventable diseases and immunization coverage in a population of high rate of illiteracy. J Trop Pediatr 1995;41:376-8. 